\title{
Involvement of pax2 in ovarian development and recrudescence of catfish: a role in steroidogenesis
}

\author{
Yarikipati Prathibha and Balasubramanian Senthilkumaran \\ Department of Animal Biology, School of Life Sciences, University of Hyderabad, \\ P.O. Central University, Hyderabad, Telangana, India
}

Correspondence should be addressed to B Senthilkumaran Email bsksl@uohyd.ernet.in

\begin{abstract}
PAX2, a member of paired box family, is an essential transcription factor for the organ development in vertebrates including teleosts, yet no evidence has been shown for its involvement in reproduction. To study this, partial- and/or full-length cDNA of pax2 was isolated from the ovary of catfish, Clarias batrachus, along with its other Pax family members, pax 1 and pax9. Tissue distribution and ontogeny expression analysis indicated the prevalence of pax 2 but not pax 1 and pax9 in ovary. Varied phase-wise expression during ovarian cycle and elevation of pax2 after human chorionic gonadotropin induction showed probable regulation by gonadotropins. Pax2 could be localized in various stages of oocytes and in follicular layer of vitellogenic and post-vitellogenic oocytes. To assess the functional significance of pax2, transient RNA silencing was performed using primary catfish ovarian follicle culture, in vitro, and in catfish, in vivo, through ovary-targeted injection of PEI-esiRNA. Pax2 siRNA treatment reduced the expression of various transcripts related to ovarian development like signaling molecules such as wnt4 and wnt5, estrogen receptors, several steroidogenic enzymes and transcription factors. These transitions in transcript levels might have been mediated by Pax2 acting upstream of wnt4/5 that may play a role in steroidogenesis and/or ovarian development along with ad4bp/sf-1 or by direct or indirect interaction with steroidogenic enzyme genes, which is evident from the change in the levels of serum estradiol-17 $\beta$ but not $17 \alpha, 20 \beta$-dihydroxy-4-pregnen-3-one. Taken together, it seems that pax2 has a plausible role during ovarian development and/or recrudescence of catfish either directly or indirectly through Wnt signaling pathway.
\end{abstract}

Journal of Endocrinology (2016) 231, 181-195

\section{Introduction}

Paired box (PAX) genes encode a family of transcription factors that are involved in the development of various tissues during early embryogenesis in vertebrates. They are known to possess paired domain and derived their name by being homologous to the Drosophila gene, 'prd' that is involved in the pair-rule segmentation (Treisman et al. 1991). There are nine Pax genes identified in humans that are divided into four subgroups based on the presence or absence of a homeodomain and an octapeptide region, and their developmental functions are assigned based on the subgroup they belong to (Blake \& Ziman 2014). 
Pax2 is known to have a role in mammalian kidney development (Torres et al. 1995), inner ear patterning and optic nerve trajectory (Torres et al. 1996) and also operates various signaling pathways (Zhou 2012).

Group of pax genes identified till date in teleosts are known to be involved in various developmental processes. Hindbrain development in teleosts is dependent on pax 1 and pax 9 , whereas pax6 plays a role in retinal development (Lakowski et al. 2007). Myogenesis is mediated by the expression of pax3 and pax7 (Kacperczyk et al. 2009, Froehlich et al. 2013, Chapalamadugu et al. 2015), whereas pax8 is an early marker for inner ear growth and is also required for otic placode development (Mackereth et al. 2005). For instance, pax2, in teleosts, plays an important role in several developmental processes such as retinal regeneration in the optic nerve head of goldfish (Parrilla et al. 2012). In zebrafish, it maintains the otic placode development in the inner ear along with pax8 (Mackereth et al. 2005). It is also required for the development of mid-hind brain boundary (Lun \& Brand 1998), kidney (Majumdar et al. 2000) and thyroid follicles in zebrafish (Wendl et al. 2002). Considering the interaction and regulatory influence of thyroid hormones on gonadal development and recrudescence (Swapna et al. 2006, Swapna \& Senthilkumaran 2007), the importance of pax genes in gonads needs to be explored. Further, the direct role of these Pax members in gonadal development, if any, has not yet been analyzed in lower vertebrates.

Catfish, Clarias batrachus, is an annual breeder that follows four reproductive phases, viz. preparatory (February-April), pre-spawning (May-June), spawning (July-August) and post-spawning/resting phase
(September-January). During the spawning phase, the membrane-bound bi-lobed ovary consists of a large number of post-vitellogenic follicles (Lehri 1968), which can be ovulated artificially for in vitro fertilization with testicular milt. The ovary undergoes morphological and physiological changes during annual reproductive cycle as per seasonal cues. Depending on the stage of ovary, the expression pattern of various transcripts undergoes changes in teleosts. In view of this, an attempt has been made to investigate the role of Pax2 in ovarian development during the reproductive cycle of catfish, primarily through expression analysis and localization and after gonadotropin induction. cDNA fragments of pax2, pax 1 and pax9 were cloned either partially or full-length to determine the tissue distribution to evaluate gonad specificity in comparison with pax2. Further, to assess the functional significance of pax 2 expression in ovarian development, transient siRNA transfection strategy was used to silence the gene expression, in vitro and in vivo. In vitro transfection was done on primary catfish ovarian follicle culture by the most common approach used for nucleic acid delivery, with the lipid-based molecule, Lipofectamine, as the transfection reagent. In vivo transfection into animal models is limited by various barriers. Of the various methods used to efficiently silence the target gene with less off-targets, the non-viral delivery method of polyethylenimine (PEI) transfection, known to be effective for even therapeutic applications (Akhtar \& Benter 2007), was chosen. After transient silencing of mRNA and protein levels of Pax2, various factors that are known to play a critical role in ovarian development of

Table 1 List of primers used for cDNA cloning.

\begin{tabular}{cl} 
Sl. no. & Primer \\
\cline { 2 - 2 } 1 & P2 DF* \\
2 & P2 DR* \\
3 & P1 DF* \\
4 & P1 DR* \\
5 & P1 5P \\
6 & P15N \\
7 & P13P \\
8 & P13N \\
9 & P25P \\
10 & P25N \\
11 & P23P \\
12 & P23N \\
13 & P2 Orf fw \\
14 & P2 Orf rv \\
\hline
\end{tabular}

\begin{tabular}{lll}
\hline Sequence $\left(5^{\prime}-3^{\prime}\right)$ & & Usage \\
\cline { 1 - 2 } GTYTCNTCYATHAACAGGAT & RT-PCR & RT-PCR \\
TCDCTYCCAGGVACCATTCC & RT-PCR \\
CCSCTKCCCAAYGCSATC & RT-PCR \\
ACRTTRTAYTTRTCRCAVAC & RACE \\
TCGCACCGGGCAATATGGAGCCGGT & RACE \\
ACGGATCCCGAGCTGTGCTAACTCCA & RACE \\
AGGCAGCAAGCCGCGAGTTACGACACCA & RACE \\
TGCATGGGAGATTCGTGACCGACTTC & RACE \\
CCGCTCGATACTGGAGGGGAAGCTGTGC & RACE \\
TCCATCAGGAGAGGGGTGGTACTGTTG & RACE \\
GCCTTGGATCGAGTGTTTGAGCGACC & RACE \\
CAACCTTACCTGGGTATCCTCCTCGT & ORF cloning \\
ATGGATATTCACTGCAAAGCAGAC & ORF cloning \\
CTAGTGGCGGTCATAGGCA &
\end{tabular}

*IUPAC nucleic acid codes are $\mathrm{B}=\mathrm{C}$ or $\mathrm{G}$ or $\mathrm{T} ; \mathrm{D}=\mathrm{A}$ or $\mathrm{G}$ or $\mathrm{T} ; \mathrm{H}=\mathrm{A}$ or $\mathrm{C}$ or $\mathrm{T} ; \mathrm{K}=\mathrm{G}$ or $\mathrm{T} ; \mathrm{M}=\mathrm{A}$ or $\mathrm{C} ; \mathrm{N}=$ any base; $\mathrm{R}=\mathrm{A}$ or $\mathrm{G} ; \mathrm{S}=\mathrm{G}$ or $\mathrm{C} ; \mathrm{V}=\mathrm{A}$ or $\mathrm{C}$ or $\mathrm{G}$; $\mathrm{W}=\mathrm{A}$ or $\mathrm{T} ; \mathrm{Y}=\mathrm{C}$ or $\mathrm{T}$. 


\section{Materials and methods}

such as steroidogenic factor 1 ( $a d 4 b p / s f-1)$, forkhead box L2 (foxl2), SRY-related high mobility group (HMG) box family member, 9b (sox $9 b)$ and estrogen receptor 1 (esr1) and 2 (esr2), which are essential for ovarian development (see Sirotkin 2010, Sudhakumari \& Senthilkumaran 2013) were chosen for analysis along with the signaling molecules of wnt (wingless-integrated (MMTV) site family) 4 and 5 (wnt4 and wnt5). In addition, serum estradiol-17 $\beta\left(\mathrm{E}_{2}\right)$ and $17 \alpha, 20 \beta$-dihydroxy-4-pregnen-3one $(17 \alpha, 20 \beta-\mathrm{DP})$ were measured as the production of these steroids in the ovary and their subsequent signaling events are critical for proper ovarian developmental processes of follicular growth, oocyte maturation and ovulation through shift in steroidogenesis (Senthilkumaran et al. 2004, Drummond 2006, Jamnongjit \& Hammes 2006). Further, the expression patterns of several transcripts encoding steroidogenic enzyme genes, such as cholesterol side-chain cleavage enzyme of cytochrome P450 family member 11 subfamily A member 1 (cyp11a1), 3 $\beta$-hydroxysteroid dehydrogenase $(3 \beta-h s d)$, 17 $\beta$-hydroxysteroid dehydrogenase type 1 and 12 (17k-hsd1 and 12), ovarian aromatase (cyp19a1a), 17 $\alpha$-hydroxylase/C17-20 lyase type 1 (cyp17a1), 20ß-hydroxysteroid dehydrogenase $(20 \beta-h s d)$ and steroidogenic acute regulatory protein (star), were analyzed.

\section{Animals and sampling}

The catfish C. batrachus fingerlings and adults used in this study were obtained by in vitro fertilization established in our laboratory (Rajakumar et al. 2012) at Hyderabad with the brood stock procured from local markets of river Ganges of Varanasi, India. Catfish rearing, feeding and maintenance were done as described earlier (Rajakumar et al. 2012). For tissue distribution study, different tissues (ovary, brain, liver, kidney, gills, intestine, muscle, heart and spleen) from adult female $(n=6)$ and male (testis) catfishes $(n=6)$ were collected during preparatory phase of reproductive cycle. For ontogeny analysis, 0 days post hatch (dph), mesonephric gonadal complex (MGC) from $5,10,30$ and $40 \mathrm{dph}$ larvae $(n=15)$ and gonads $(n=15)$ from the sexual differentiation stage of $50 \mathrm{dph}$ till adult $(50,100,150,200,250$ and $365 \mathrm{dph})$ were collected separately from males and females. As per the seasonal reproductive cycle characterized histologically in our laboratory, ovaries and testes were collected $(n=10)$ at different months for phase-wise analysis. All the tissues were stored at $-80^{\circ} \mathrm{C}$ until total RNA preparation. Animal maintenance, experimentation and killing were done following the general institutional animal ethical guidelines, University of Hyderabad.

Table 2 List of primers used for qPCR analysis.

\begin{tabular}{l} 
Gene name/symbol \\
\hline pax2 \\
pax1 \\
pax9 \\
wnt4 \\
wnt5 \\
foxl2 \\
sox9b \\
star \\
ad4bp/sf-1 \\
cyp17a1 \\
cyp11a1 \\
$17 \beta-h s d 1$ \\
$17 \beta-h s d 12$ \\
$20 \beta-h s d$ \\
$3 \beta-h s d$ \\
cyp19a1a \\
esr1 \\
esr2 \\
18S rRNA
\end{tabular}

\begin{tabular}{l} 
Forward primer $\left(5^{\prime}-3^{\prime}\right)$ \\
\hline ATCCTGGGCAGGTACTATGA \\
ACCGGCTCCATATTGCCCG \\
CAGCTCGATTAGTCGGATCCT \\
AGCAACTGGCTCTATCTGG \\
TCATGGTGGTCTCTGGCTATG \\
CATGGCTATACGCGACAGCTC \\
GAGACCCAGTCAGGCCACAG \\
TCGTCCGAGCCGAGAACGG \\
TCACTATGGCCTGCTCACCTG \\
CCATGGCTCCAGCTCTTTCC \\
TCAACCAAGCGGACCACTGT \\
GACATCCTGGTGTGTAATGCAGG \\
AGCCATCGAGAGCAAGTACCATGT \\
GAATCGCCTTCAAAATGG CTG \\
GAGGTAAATGTGAAAGGTACCAA \\
AGGTCCCTGGTTTTGTCTG \\
TGTCCGGCCACCAATCA \\
TGTCCTGCAACCAACCA \\
GCTACCACATCCAAGGAAGGCAGC
\end{tabular}

Reverse primer $\left(5^{\prime}-3^{\prime}\right)$

GGATCTCCCACGCGAACAT

TATCGCACACTCCATCTGCT

GTACTTTAGTCCCTGTGGCTG

ACTCGTCGATGGCAAGCTG

ATGTACTGCATGTGGTCCTG

CCAGTAGTTCCCCTTCCTCTC

AGGGTCTCGATGTGGGCCA

TGCCTCCTCCACTCCACTG

CGCTTGTACATGGGGCCGAAC

CAGTAAGACCAACATCCTGAGTGC

TCAGGATGCCGTGCCAACTC

CTGCCTGTGACCAGGATCCGT

AAGCCGAGTCATCTGACAAACCGA

AACATTCACCACCCTTCCTCC

TAGTACACAGTGTCCTCATGG

TGCAGATGGCCTGCTGAGG

GTGTCTCCTGCTGTGCTTCAT

CCTCTGCTGAGACCCCCACGA

CGGCTGCTGGCACCAGACTTG

\begin{tabular}{l} 
Accession number \\
\hline KU301794 \\
KX499463 \\
KX499464 \\
KX499465 \\
KX529112 \\
HQ680981 \\
HM149259 \\
FJ793811 \\
HQ680985 \\
FJ790422 \\
KF739411 \\
HQ680984 \\
JN848590 \\
FJ031008 \\
HQ680983 \\
GU220075 \\
X84743 \\
Teves et al. (2003)* \\
KM018296
\end{tabular}

*No accession number available.

http://joe.endocrinology-journals.org
DOI: 10.1530/JOE-16-0103
๑) 2016 Society for Endocrinology Printed in Great Britain
Published by Bioscientifica Ltd. 


\section{Molecular cloning of different cDNA fragments of Pax from catfish}

Adult catfish ovary $(100 \mathrm{mg}$ ) was used to isolate total RNA using TRI reagent (Sigma). The quantity was analyzed by NanoDrop spectrophotometer (ND-2000, NanoDrop Technologies, Wilmington, DE, USA) and its 260/280 ratio was obtained as a basis to ensure its purity. To check its integrity, denaturing gel electrophoresis was performed, which showed two sharp and clear bands of $28 \mathrm{~S}$ and $18 \mathrm{~S}$ rRNA in approximately 2:1 ratio without smear, indicating intact RNA. The cDNA was prepared with SuperScript III according to the manufacturer's instructions (Invitrogen), followed by DNase I treatment to exclude DNA contamination, using $5 \mu \mathrm{g}$ of total RNA after checking its quality by amplifying the $\beta$-actin gene. To isolate partial cDNA fragments of pax 1 and pax2, degenerate primers were designed (Table 1) based on the available nucleotide sequences of teleosts and other vertebrates from NCBI GenBank database. Partial fragments of pax1 ( 250bp) and pax2 ( 620 bp) obtained from the PCR amplifications performed at $94^{\circ} \mathrm{C}(1 \mathrm{~min})$ and 35 cycles of $94^{\circ} \mathrm{C}(30 \mathrm{~s})$, $53^{\circ} \mathrm{C}(30 \mathrm{~s}), 72^{\circ} \mathrm{C}(1 \mathrm{~min})$ and $72^{\circ} \mathrm{C}(10 \mathrm{~min})$ using respective degenerate primers (P2DF, P2DR and P1DF, P1DR) listed in Table 1 were cloned into the pGEM-T easy vector (Promega) and sequenced bidirectionally. Gene-specific primers (Table 1) were designed based on the sequence information of the partial cDNAs to obtain full-length cDNA through RACE strategy (Clontech). All nested PCR fragments cloned into the pGEM-T easy vector (Promega) after gel purification were sequenced bidirectionally. Interestingly, cDNA fragment of pax9 was amplified while performing 3' RACE for pax1. All overlapping DNA fragments were assembled, and the full-length cDNA sequencing data were analyzed using Lasergene software 7.1.0 (DNASTAR, Madison, WI, USA) and verified using the NCBI-BLAST and ClustalW2 under default parameters.

\section{Sequence and phylogenetic analysis}

Pax2 amino acid (aa) sequences of other vertebrates from GenBank were used for the ClustalW alignment and phylogenetic analysis with the deduced aa sequence of catfish Pax2. The GenBank accession numbers of sequences used are Danio rerio Pax2a (NP_571259.1), D. rerio Pax2b (NP_571715.1), Dicentrarchus labrax (CBN81534.1), Oryzias latipes (CAB09696.1), Ovis aries (NP_001171523.1), Gallus gallus (NP_990124.1), Mus musculus (NP_035167.4), Rattus norvegicus (NP_001099831.1), Xenopus laevis (CAA71205.1), Homo sapiens (NP_000269.2) and C. batrachus (KU301794). ClustalW2 (http://www.ebi. ac.uk/Tools/msa/clustalw2/) was used for the multiple alignment. Jalview 2.8. ClustalW (http://clustalw.ddbj. nig.ac.jp/) was used to construct the phylogenetic tree by neighbor-joining method, and it was displayed using TreeView 1.6.6. The values represent bootstrap scores out of 1000 trials, indicating the credibility of each branch.

\section{Quantitative real-time PCR (qPCR)}

One microgram of total RNA, extracted using TRI reagent (Sigma) as per the manufacturer's instructions, was used with random hexamers for the reverse transcription using Verso Reverse Transcriptase (Thermo Scientific), followed by DNase I treatment to exclude genomic DNA. For all qPCR analyses, specific primers of all transcripts including wnt 4 and wnt5 cloned from our laboratory (Table 2) were designed for the amplicon length of $150-250 \mathrm{bp}$ with at least one primer to span the exon-exon junction with the existing fish and mammalian genome information as basis. To check the specificity and efficiency of the primers used, semi-quantitative PCR was performed before proceeding to $\mathrm{qPCR}$, and the PCR product was sequenced. All reactions were performed in triplicates for three different samples with Power SYBR Green PCR Master Mix (Applied Biosystems) in an ABI Prism 7500 fast thermal cycler (Applied Biosystems) according to the manufacturer's universal thermal cycling conditions. After performing melting-curve analysis to check the specificity of the PCR amplification, cycle threshold (Ct) values obtained from the exponential phase of PCR amplification were used for generating $\triangle \mathrm{Ct}$ value, in which $18 S \mathrm{rRNA}$ is taken for normalization against the expression of target gene. From the preliminary experiments of this study, as
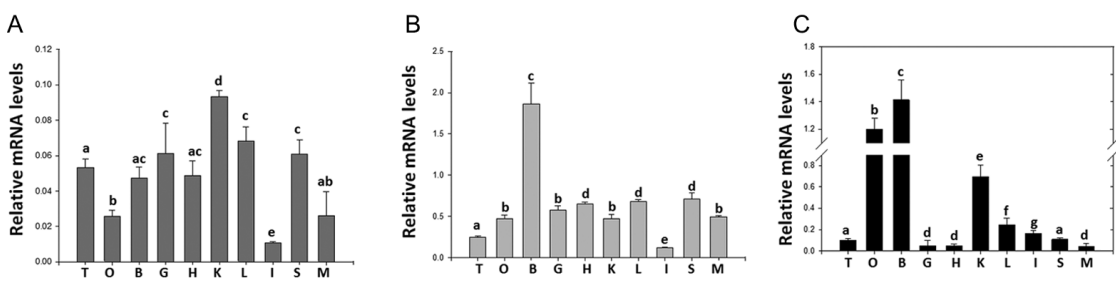

Figure 1

Relative mRNA levels of (A) pax1, (B) pax9 and (C) pax2 in different tissues of adult catfish. All data were expressed as mean \pm S.E.M. Means with different letters differ significantly $(P<0.05$; Kruskal-Wallis one-way ANOVA on ranks followed by SNK test). T, Testes; O, Ovary; B, Brain; G, Gill; H, Heart; K, Kidney; L, Liver; I, Intestine; S, Spleen; M, Muscle. http://joe.endocrinology-journals.org DOI: 10.1530/JOE-16-0103
๑) 2016 Society for Endocrinology Printed in Great Britain 
per the validation done based on Radonić et al. (2004), $18 S$ rRNA (KM018296.1) normalization was found to be efficient and constitutive with the lowest transcription range compared with other reference genes such as $\beta$-actin (EU527190.2) and gapdh (KC414932.1). The evaluation of gene expression was done by $2^{-\Delta \mathrm{Ct}}$ method.

\section{Human chorionic gonadotropin (hCG) induction, in vivo}

Acclimated adult female catfishes $(n=10)$ used for this experiment were injected with a single dose $(1000 \mathrm{IU} / \mathrm{kg}$ body weight) of hCG (Pubergen, Uni-Sankyo Pvt. Ltd., Hyderabad, India) for the induction, whereas control fishes were administered with physiological saline $(0.6 \% \mathrm{NaCl}$ W/V) during mid-preparatory phase (March). The ovaries were collected separately for saline- and hCG-induced fishes at different time intervals $(0,6,12,18$ and $24 \mathrm{~h})$ after killing them by anesthetizing in mild ice-cold water having MS 222 (Sigma). The relative expression of pax 2 was analyzed using qPCR as described previously.

\section{In situ hybridization (ISH)}

Ovary $(100 \mathrm{mg})$ of adult catfish $(n=10)$ in pre-spawning phase was fixed in 4\% PFA in PBS (phosphate buffered saline, $\mathrm{pH} 7.4$ ) at $4^{\circ} \mathrm{C}$ overnight. PFA-fixed ovary was washed four times with PBS for a cycle of 10 min each at $4^{\circ} \mathrm{C}$. Embedding was done in OCT compound medium (Leica Microsystems) onto a cryomold (Tissue-Tek,
Sakura Finetek Europe B.V., AJ Alphen aan den Rijn, The Netherlands) and stored at $-80^{\circ} \mathrm{C}$ until sectioning. The OCT-embedded tissues were cross-sectioned $(10 \mu \mathrm{m})$ on to poly-L-Lysine coated slides using a cryostat (Leica CM1850, Leica Microsystems) and were allowed to dry overnight on a hotplate at $42^{\circ} \mathrm{C}$. The pax 2 probe was prepared from pGEM-T easy-pax 2 cDNA ( $620 \mathrm{bp})$ by linearization using restriction enzymes (zero cutters for insert). Based on the sequence data of pGEM-T-pax 2 cDNA, either T7 or SP6 RNA polymerase was used for sense and antisense 'CRNA' probe preparation using digoxigenin (DIG; Roche Diagnostics $\mathrm{GmbH}$ ) -based in vitro transcription. ISH protocol was performed as per the method described in Rajakumar and Senthilkumaran (2014a).

\section{Western blot analysis}

The antibodies used to carry out western blot analyses are Pax2 (Life Span Biosciences Inc. LS-C102856)/Wnt4 (Life Span Biosciences Inc. LS-C109642/61282) polyclonal antibodies raised against the conserved C-terminal regions of human Pax 2 and Wnt4, which showed $80 \%$ homology with the conserved region of catfish Pax2 and Wnt4, respectively. Ovarian tissue homogenate was extracted from adult catfish ovary with homogenization buffer containing $50 \mathrm{mM}$ Tris-HCl, pH 7.4, $150 \mathrm{mM} \mathrm{NaCl}$, $1 \mathrm{mM}$ DTT, and ProteoBlock protease inhibitor cocktail (Thermo Scientific), followed by a standard protocol
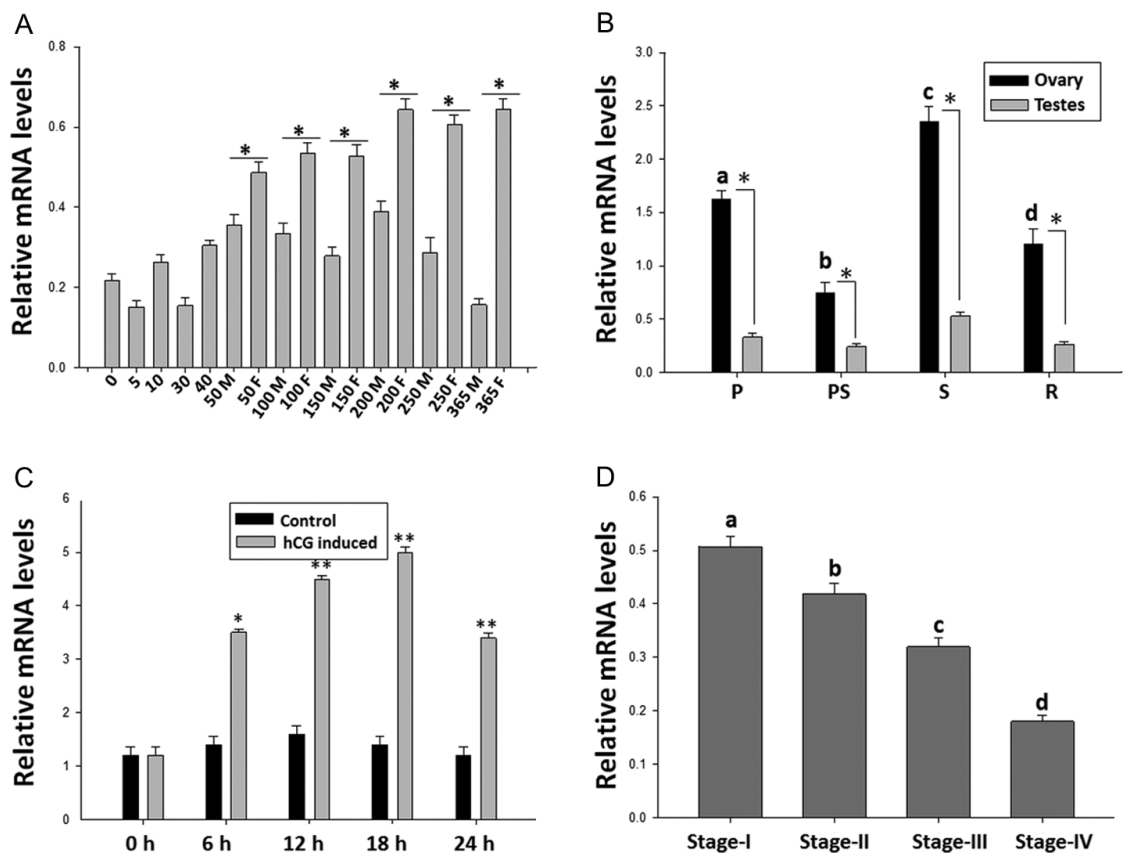

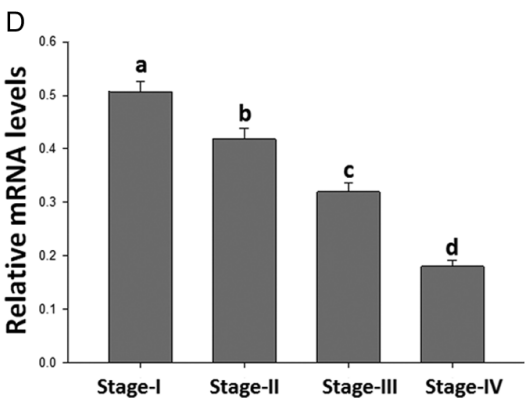

Figure 2

Relative mRNA levels of pax2 at (A) various stages of gonadal development from 0 to 365 days post hatch, (B) different phases of ovarian and testicular reproductive cycle, (C) diverse time intervals after hCG induction in ovary and (D) different developmental stages of ovarian follicles. All data were expressed as mean \pm s.E.M. *indicates means with significantly higher pax2 mRNA levels compared with the corresponding opposite sex of the same age group $(P<0.05$; ANOVA followed by SNK test). Means with different letters differ significantly $(P<0.05$; Kruskal-Wallis one-way ANOVA on ranks followed by SNK test). *** indicates means with significantly higher pax2 mRNA levels compared with the $0 \mathrm{~h}$ and parallel control $(P<0.05, P<0.01$, ANOVA followed by SNK test). $M$, Male; $F$, Female; P, Preparatory; PS, Pre-spawning; $S$, Spawning; R, Post-spawning/Resting Phase. I. Peri-nucleolar, II. Pre-vitellogenic, III. Vitellogenic and IV. Post-vitellogenic oocytes. http://joe.endocrinology-journals.org DOI: 10.1530/JOE-16-0103
๑) 2016 Society for Endocrinology Printed in Great Britain 
for western blot as described earlier in Rajakumar and Senthilkumaran (2014a). The blots were developed with commercial enhanced chemiluminescence (ECL) western blotting substrate as per the manufacturer's instructions (Promega). Same protocol was followed for anti- $\beta$-tubulin antibody, which was used as an equal loading control. For negative control, muscle or intestine tissue homogenate protein was used.

\section{Immunohistochemistry}

Adult catfish $(n=10)$ ovary was fixed and sectioned as described previously. The sections were rinsed with PBS, blocked with goat serum and incubated with antiPax2 polyclonal antibody (1:1000) or pre-adsorbed antibody (for negative control) overnight at $4^{\circ} \mathrm{C}$ in a humid chamber. Further, HRP-conjugated secondary antibody (Merck Bangalore Genei) incubation was done for $2 \mathrm{~h}$ at RT. VECTASTAIN Elite ABC reagent (Vector Laboratories, Burlingame, CA, USA) incubation was done for $30 \mathrm{~min}$ before developing them with commercially available 3,3'-diaminobenzidine (DAB) and $\mathrm{H}_{2} \mathrm{O}_{2}$ (Vector Laboratories) as substrate. After developing, sections were counterstained with hematoxylin (Qualigens Fine Chemicals, Worli, Mumbai, India), dehydrated using a graded ethanol series and mounted using DPX mountant. The images were acquired using Q capture Pro 6 software (Quantitative Imaging Corporation Surrey, BC, Canada) with Micropublisher 3.3 RTV-CCD camera in a CX41 Olympus microscope (Olympus Corporation).

\section{Primary catfish ovarian follicle culture (mixed)}

Primary ovarian follicle culture was done as per the protocol of $\mathrm{Li}$ and coworkers (2012) with minor modifications. Catfish $(n=10)$ ovaries in preparatory phase, which are abundant in transcripts essential for reverting to functional stage, were dissected, and the follicles (pre-vitellogenic stage) were dispersed gently using a sterile plastic pipette. The follicular culture has
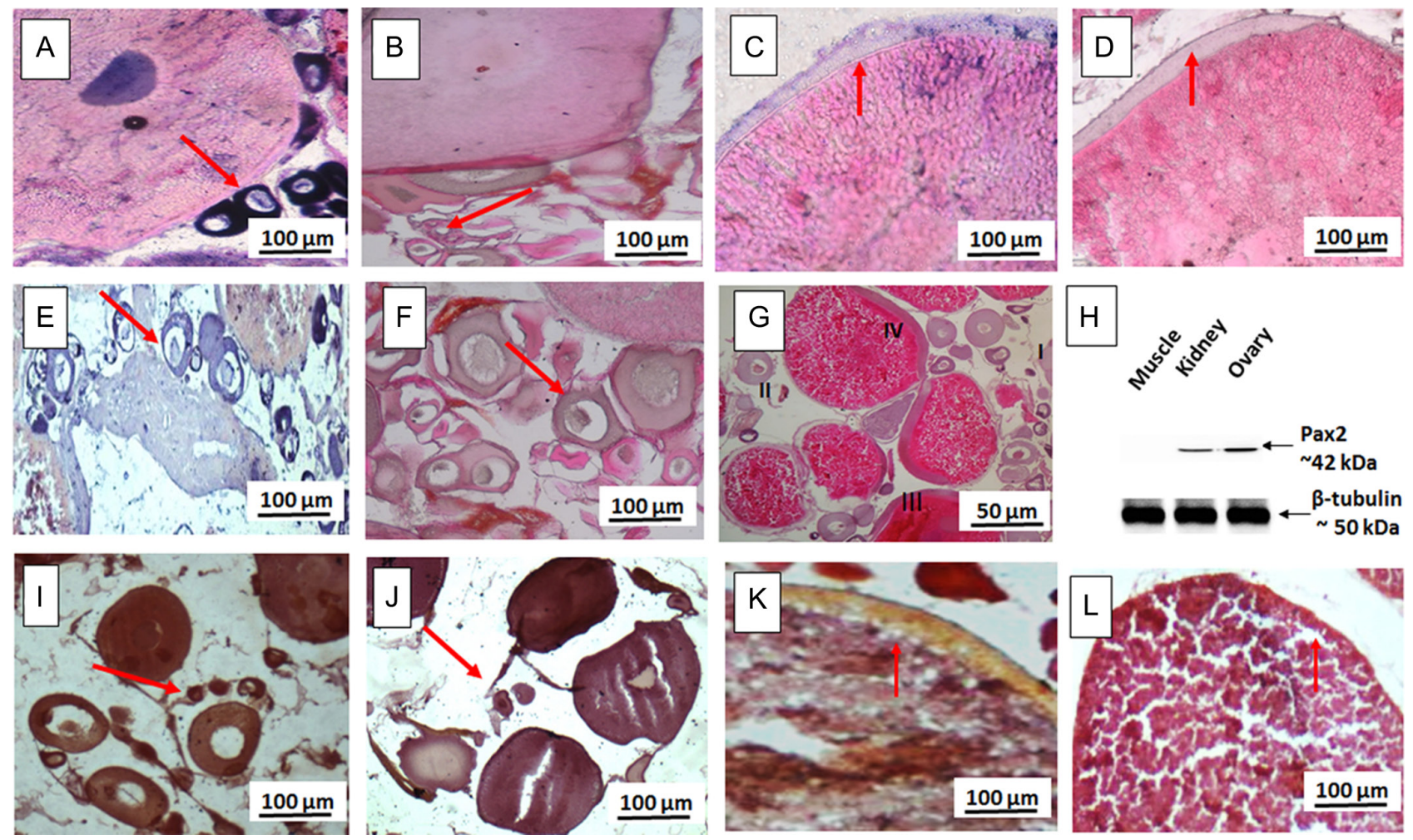

Figure 3

Localization of mRNA of pax 2 in the adult catfish ovary with ( $A, C$ and $E$ ) anti-sense probe and ( $B, D$ and $F)$ sense probe showing the presence or absence of transcripts in different stages of ovarian follicles. (G) Hematoxylin and eosin staining of ovary showing different types of follicles. I. Peri-nucleolar, II. Pre-vitellogenic, III. Vitellogenic and IV. Post-vitellogenic oocytes. (H) Western blot analysis demonstrating the antibody characteristics of Pax2. Pax2 antibody was detected as a putative $\sim 42 \mathrm{kDa}$ band in kidney and ovary but not in muscle, whereas $\beta$-tubulin showed no such differences. (I, K) Localization of Pax2 in the adult catfish ovary using immunohistochemistry. $(\mathrm{J}, \mathrm{L})$ No immunoreactive signal was evident in the negative control with pre-adsorbed Pax2 antibody with excess peptide of Pax2. Arrows indicate ovary sections showing the presence or absence of signals. A full colour version of this figure is available at http://dx.doi.org/10.1530/JOE-16-0103.

http://joe.endocrinology-journals.org DOI: $10.1530 / \mathrm{JOE}-16-0103$
๑) 2016 Society for Endocrinology Printed in Great Britain
Published by Bioscientifica Ltd 


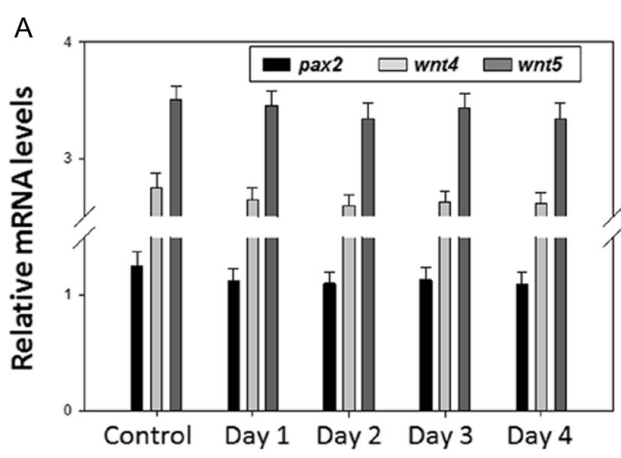

B

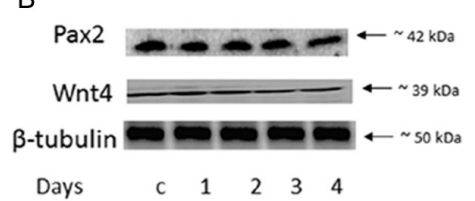

Days
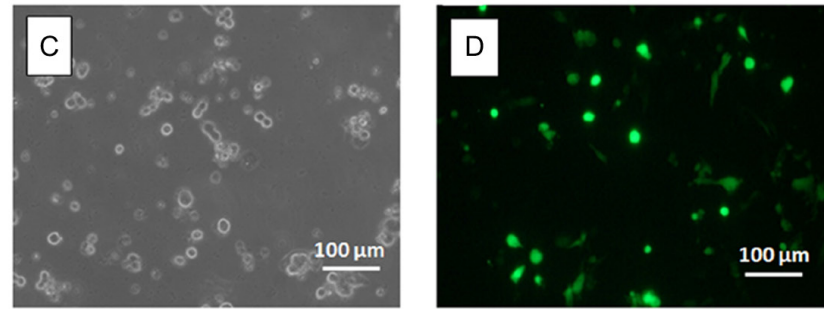

Figure 4

(A) Relative mRNA levels of pax2, wnt4 and wnt5. (B) Western blot analysis of Pax2 and control $\beta$-tubulin in the primary culture of ovarian follicles for 4 days. C, control. (C) Representative phase-contrast image of primary cultures of catfish ovarian follicles and (D) after control siRNA transfection (to check the efficiency). A full colour version of this figure is available at http://dx.doi.org/10.1530/JOE-16-0103. different cell types and was hence mentioned as mixed. The dispersed follicles $(n=200)$ were washed with $60 \%$ L-15 medium (Sigma) several times. The filtered follicles were then washed several times with medium M199 (Gibco-BRL, Invitrogen) and plated into $10 \mathrm{~cm}$ culture dishes. The follicles were grown for 6 days at $28^{\circ} \mathrm{C}$ in M199 with 10\% FBS (Gibco-BRL) with a change of medium after 3 days. Further, the follicular cells during the 6-day incubation were suspended by trypsinization, washed and sub-cultured into 24-well plates in Dulbecco's Modified Eagle's Medium (DMEM).

\section{siRNA transfection in vitro}

The primary culture cells $(100,000$ cells/well) obtained from ovarian follicles were grown in DMEM with 10\% FBS, $2 \mathrm{mM}$ L-glutamine, and antibiotic and antimycotic solution (Gibco-BRL) at $37^{\circ} \mathrm{C}$ supplemented with $5 \%$
$\mathrm{CO}_{2}$. Transfection was done using Lipofectamine 2000 reagent (Invitrogen) as per manufacturer's protocol. Custom-made catfish-specific MISSION esiRNA (Sigma), an endoribonuclease-prepared heterogeneous mixture of siRNA pools with multiple triggers and less off-target effects, synthesized from the conserved region of Pax2 (250-386 aa; GenBank accession no. KU301794), was used for the experiments. The fluorescent universal negative control esiRNA was purchased from Sigma (Cat. No. SIC00710NMOL), for control siRNA experiments. These experiments were performed as per the institutional biosafety committee ethical guidelines, University of Hyderabad.

\section{siRNA injection in vivo}

Adult female catfish $(n=6)$ at the preparatory phase (March) used for our experiments were obtained by in vitro fertilization followed by rearing and
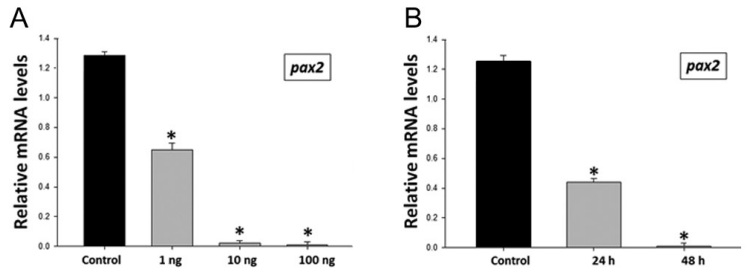

C
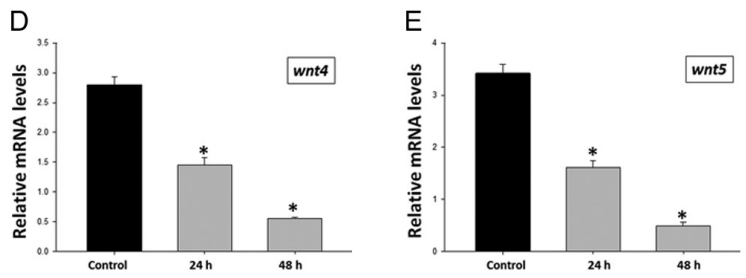
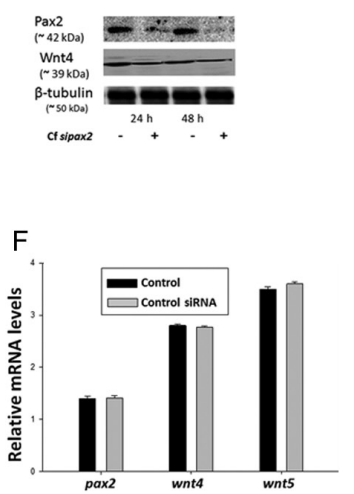

Figure 5

Relative mRNA levels of pax 2 in the ovary of catfish after silencing of primary culture of follicles (A) at different concentrations after $48 \mathrm{~h}$ (B) at $10 \mathrm{ng}$ concentration after different periods. (C) Western blot analysis after silencing Pax2 at $10 \mathrm{ng}$ concentration after different periods. Relative mRNA levels of (D) wnt4 and (E) wnt5 in the ovary of catfish after silencing of pax 2 in primary culture of follicles at $10 \mathrm{ng}$ concentration after different periods. (F) Relative mRNA levels of pax2, wnt4 and wnt5 after transfecting with control siRNA. The relative expression was normalized with 185 rRNA expression, and the values were calculated using comparative ct method. All data were expressed as mean \pm S.E.M. ( ${ }^{*} P<0.05$; ANOVA followed by SNK test). 
maintenance in our laboratory as explained earlier. Fish were briefly anesthetized before surgery with $100 \mathrm{mg} / \mathrm{L}$ of MS 222 (Sigma) in mild ice-cold water following general animal ethical guidelines. A minor incision was made at the abdomen with the help of sterile scalpel and a syringe loaded with $1 \mu \mathrm{g}$ of siRNA complexed with linear PEI (Sigma) was injected directly into the ovary bilaterally. The absorption of the PEI-siRNA complex into the ovary was checked with trypan blue for mock control. Then the incision was sutured by catgut under sterile conditions, and fishes were kept in water at ambient temperature for a few minutes to recover from anesthesia. The same procedure was followed for the control siRNA treatment. The injected fish were maintained in different tanks holding water of $50 \mathrm{~L}$ capacity with continuous aeration, and replenishment of water was done for the control and treated for 3 days with regular food supply. After 3 days, the fishes were killed for the analysis of their ovarian tissues.

\section{Enzyme immunoassay (EIA) for $E_{2}$ and $17 \alpha, 20 \beta-D P$}

Levels of $\mathrm{E}_{2}$ and $17 \alpha, 20 \beta$-DP in serum were measured in the control and after siRNA transfection by EIA by following the manufacturer's (Cayman) protocol. Intra- and inter-assay variations were within the limits specified in the manufacturer's protocol. The sensitivity of detection limit for $\mathrm{E}_{2}$ and $17 \alpha, 20 \beta$-DP were $20 \mathrm{pg} / \mathrm{mL}$ and $4 \mathrm{pg} / \mathrm{mL}$, respectively. The cross-reactivity of the $\mathrm{E}_{2}$ antisera with estrone is $12 \%$, with estradiol17 -glucuronide is $10 \%$ and with estriol is $0.3 \%$. Anti-17 $\alpha, 20 \beta$-DP serum is $100 \%$ specific with minimal cross-reactivity with 20 $\beta$-hydroxyprogesterone (0.01\%) and $17 \alpha, 20 \alpha$-dihydroxy progesterone $(0.004 \%)$. Assays were performed in triplicates for each independent sample, and serum sample dilutions were in parallel with the standard dilutions.

\section{Statistical analysis}

All data are presented as means of different samples with standard error of the mean (s.E.M.). All data either passed normality and homogeneity tests or were compared by Kruskal-Wallis one-way analysis of variance (ANOVA) on ranks, followed by Student-Newman-Keuls' (SNK) post hoc test. All statistical analyses were performed using SigmaPlot 11.0 software (Systat Software Inc., Chicago, IL, USA). A probability of $P<0.05$ was considered statistically significant.

\section{Results}

\section{Molecular cloning of different CDNA fragments of Pax} from catfish and phylogenetic analysis

Partial cDNA fragment of $\sim 620 \mathrm{bp}$ obtained from catfish was confirmed as pax 2 by NCBI-BLAST search, and the nucleotide sequence data were used to design specific primers for $5^{\prime}$ and $3^{\prime}$ RACE. After aligning the sequences amplified through $5^{\prime}$ and $3^{\prime}$ RACE, the ORF obtained was of $\sim 1164 \mathrm{bp}$ encoding $\sim 387$ aa with deduced molecular weight of $\sim 42 \mathrm{kDa}$. The sequences obtained at $5^{\prime}$ UTR was of $\sim 534 \mathrm{bp}$ and $3^{\prime}$ UTR was of $\sim 626 \mathrm{bp}$ with poly- $\mathrm{A}^{+}$tail.
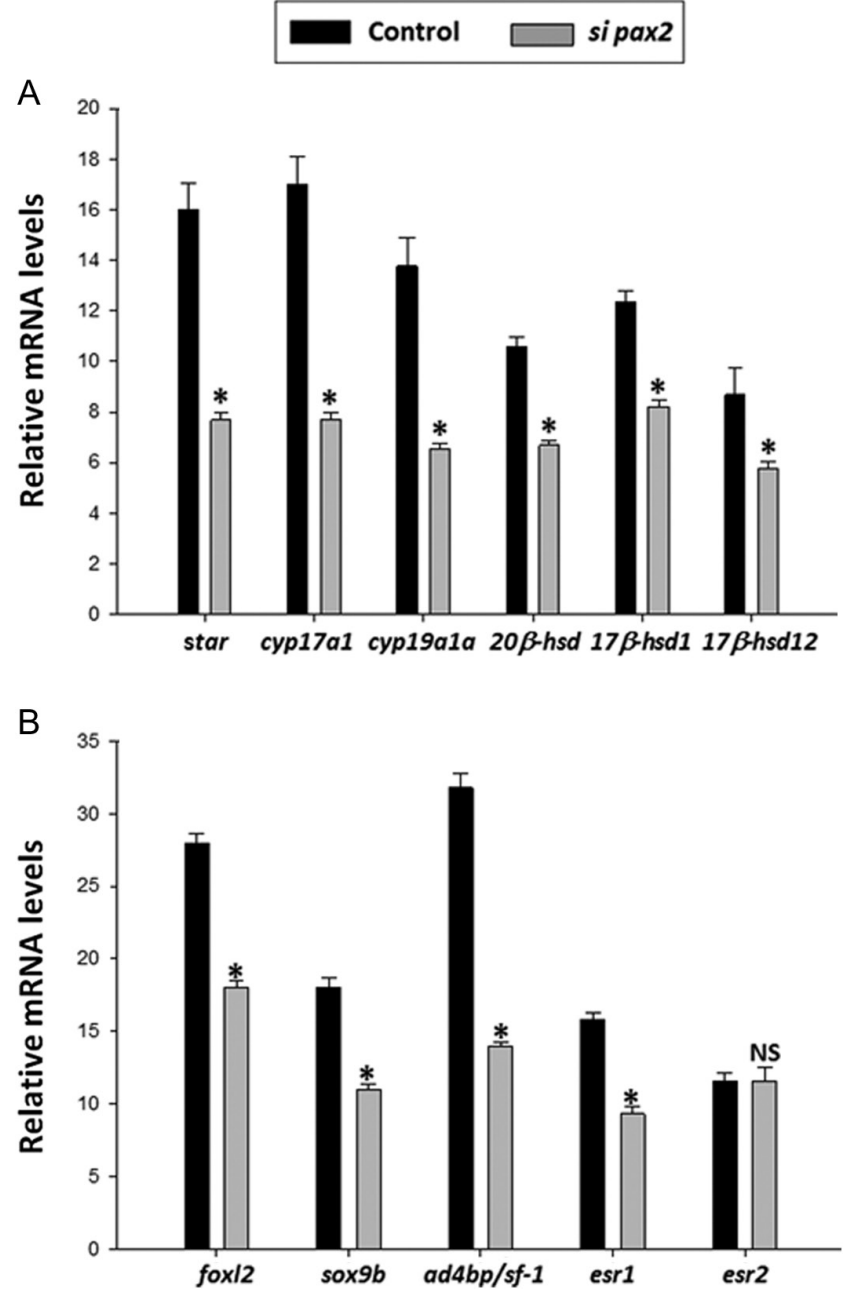

Figure 6

Relative mRNA levels of (A) star and steroidogenic enzymes such as

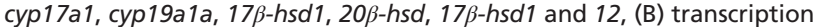
factors, fox 12 , sox $9 \mathrm{~b}$ and $a d 4 \mathrm{bp} / \mathrm{sf}-1$ and estrogen receptors, esr 1 and esr2 in the control and after silencing of primary culture of ovarian follicles, in vitro. The relative expression was normalized with 185 rRNA expression, and the values were calculated using comparative ct method. All data were expressed as mean \pm S.E.M. ( ${ }^{*} P<0.05$; ANOVA followed by SNK test). NS, not significant.

Published by Bioscientifica Ltd. 
The full-length cDNA fragment obtained was of $\sim 2.3 \mathrm{~kb}$ and was submitted to GenBank (KU301794). The partial cDNA fragment of $\sim 250$ bp of pax1 was used to design specific primers for obtaining full-length fragment of $\sim 1.5 \mathrm{~kb}$ with the RACE cDNA fragments of $5^{\prime}$ end and $3^{\prime}$ end. At the $3^{\prime}$ end, two fragments, with homology to pax1 ( 1 kb) and pax9 ( $900 \mathrm{bp})$, were obtained and were submitted to GenBank (pax1 (KX499463) and pax9 (KX499464)). The deduced aa sequence obtained for Pax2 from catfish showed high homology for the conserved paired box domain (16-141 aa), DNA-binding helix-turn-helix motif (37-139 aa) and C-terminal Pax2 domain (278-386 aa) with other vertebrate species aligned on multiple sequence alignment. The phylogenetic analysis showed that it forms a clade with its counterparts from other teleost species with high similarity (figure not shown).

\section{Expression levels of pax1, pax 9 and pax 2 in different tissues of adult catfish}

The expression of pax1 (Fig. 1A) and pax9 (Fig. 1B) analyzed in different tissues of adult catfish showed ubiquitous nature in all tissues with higher levels in brain. However, pax2 (Fig. 1C) showed dominance in brain, ovary and kidney in comparison with lower levels observed in other tissues.

\section{Expression levels of pax2 during gonadal ontogeny and reproductive cycle, after hCG induction and in different stages of ovarian follicles of catfish}

The relative expression pattern of pax 2 from $0 \mathrm{dph}$ till adult revealed an increase from 0 to $40 \mathrm{dph}$. The expression pattern from $50 \mathrm{dph}$ to adult analyzed in both males and females showed significantly higher levels $(P<0.05)$ in ovary compared with testis (Fig. 2A). The analysis of pax 2 expression during different phases of ovarian reproductive cycle of catfish showed its higher levels in preparatory and spawning phases compared with those in other phases (Fig. 2B) and are significantly $(P<0.05)$ high in levels compared with respective testicular phases (Fig. 2B). A single dose of hCG induction to catfish, in vivo, significantly increased the expression $(P<0.05$; $P<0.01$ ) pattern at 6,12 and $18 \mathrm{~h}$ and decreased at the end period of $24 \mathrm{~h}$ compared with the parallel controls and at $0 \mathrm{~h}$ period (Fig. 2C). The relative expression of pax 2 in different stages of the ovarian follicles showed significantly $(P<0.05)$ high levels in peri-nucleolar and pre-vitellogenic oocytes followed by vitellogenic and post-vitellogenic oocytes (Fig. 2D).

\section{Localization of pax2 mRNA and protein in catfish ovary}

Localization of mRNA of pax 2 in the ovary of catfish by ISH revealed its presence in peri-nucleolar, pre-vitellogenic, vitellogenic and follicular layer of vitellogenic and postvitellogenic oocytes with antisense probe (Fig. 3A, C and E),
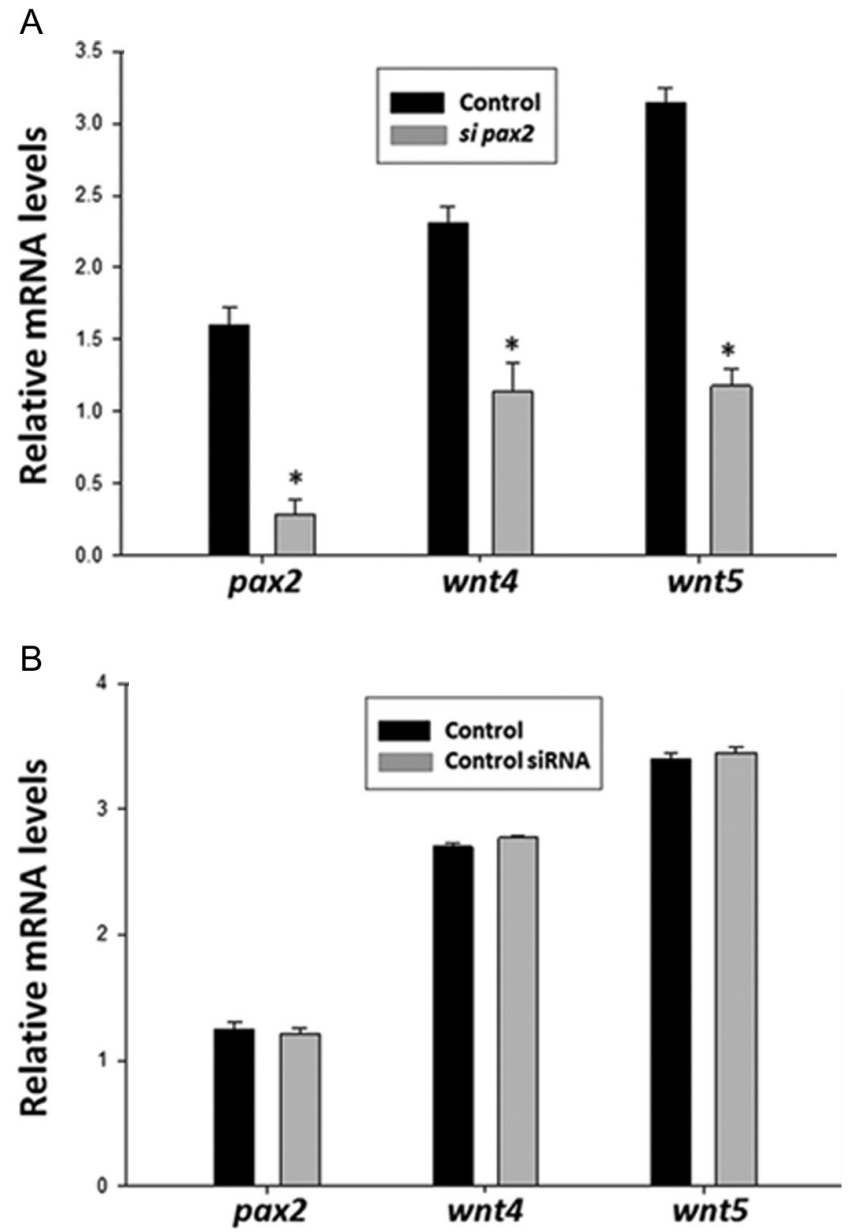

C

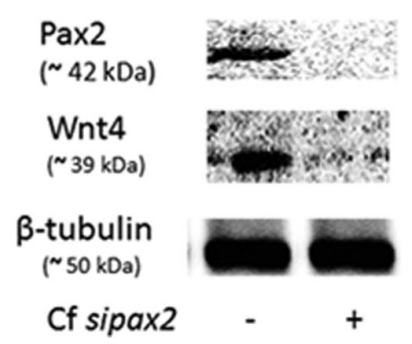

Figure 7

Relative mRNA levels of pax2, wnt4 and wnt5 in the control and (A) after silencing of pax2, (B) after silencing with control siRNA, (C) Western blot analysis showing silencing Pax2 and Wnt4 of proteins after silencing with PAX2, in the ovary of catfish, in vivo. The relative expression was normalized with 185 rRNA expression, and the values were calculated using comparative ct method. All data were expressed as mean \pm S.E.M. $\left({ }^{*} P<0.05\right.$; ANOVA followed by SNK test).

Published by Bioscientifica Ltd. 
whereas sense probe elicited no signal, and it had only the counterstain (Nuclear Fast Red) used (Fig. 3B, D and F). The stages of follicles can be observed clearly with hematoxylin and eosin-stained ovarian sections (Fig. 3G). Immunoreactivity observed for Pax 2 in the ovary of catfish with heterologous antibody gave single specific band of Pax2 of $\sim 42 \mathrm{kDa}$ (Fig. $3 \mathrm{H}$ ) and also showed typical localization pattern like ISH (Fig. 3I and K). Immunoreactivity was completely absent when pre-absorbed Pax 2 antibody with excess peptide of Pax 2 was used as a control (Fig. 3J and L), which confirmed the antibody specificity.

\section{Silencing of pax2 in primary culture of catfish ovarian follicles, in vitro at mRNA and protein levels}

The transcript expression levels observed for pax2, wnt4 and wnt5 for 4 days of primary culture cells showed a constitutive pattern, before transfection with siRNA of pax2 (Fig. 4A), and the protein levels of Pax2 and Wnt4 were also found to be stable (Fig. 4B). The transfection efficiency of primary follicle culture cells (Fig. 4C) was analyzed and confirmed with control siRNA transfection (Fig. 4D). The expression of pax2 reduced significantly $(P<0.05)$ to $50 \%$ on silencing at $1 \mathrm{ng}$ concentration, whereas at $10 \mathrm{ng}$ and $100 \mathrm{ng}$ concentrations, the transcript levels were completely reduced $(P<0.001)$ compared with control (Fig. 5A), after $48 \mathrm{~h}$. The pax 2 levels at $10 \mathrm{ng}$ concentration after $24 \mathrm{~h}$ reduced to $40 \%$, and these levels were completely knocked down after $48 \mathrm{~h}$ compared with control (Fig. 5B). Pax2 protein levels were also significantly reduced at $10 \mathrm{ng}$ concentration after $48 \mathrm{~h}$, and protein levels of Wnt 4 were found to be less compared with those of control antibody (Fig. 5C), $\beta$-tubulin (Ana Spec Inc., \# 55691s), in which no change was observed. Considering these data, primary cultured cells silenced with (Si)pax2 at $10 \mathrm{ng}$ concentration for $48 \mathrm{~h}$ were taken for further analysis of transcript levels of genes chosen for the study. Further, analysis of different transcripts (see below) pertaining to ovary-related genes has strengthened the quality of follicular cell primary culture characteristics.

\section{Change in the expression of various transcripts involved in the ovarian development after silencing pax 2 in primary culture of catfish ovarian follicles, in vitro}

The transcript levels of wnt4 (Fig. 5D) and wnt5 (Fig. 5E) reduced by $50 \%$, significantly $(P<0.001)$ on silencing pax 2 after $24 \mathrm{~h}$, which were further reduced to $80 \%$ by $48 \mathrm{~h}$ compared with the control in which the control siRNA did not show any significant change (Fig. 5F).
The expression of star, cyp17a1 and cyp19a1a reduced by $50 \%$, significantly $(P<0.001)$, whereas the expression of $20 \beta$-hsd reduced by $30 \%$, significantly $(P<0.001)$, compared with that of the controls (Fig. 6A). 17 $\beta$-hsd 1 and 12 significantly $(P<0.05)$ reduced by $20 \%$ and $15 \%$, respectively (Fig. 6A). The expression of foxl2 and sox $9 \mathrm{~b}$ significantly $(P<0.05)$ reduced by $30 \%$ (Fig. 6B). The expression of $a d 4 b p / s f-1$ reduced by $60 \%$, whereas that of esr1 reduced significantly $(P<0.001)$ by $30 \%$, and there was no change in esr2 compared with that in controls (Fig. 6B).
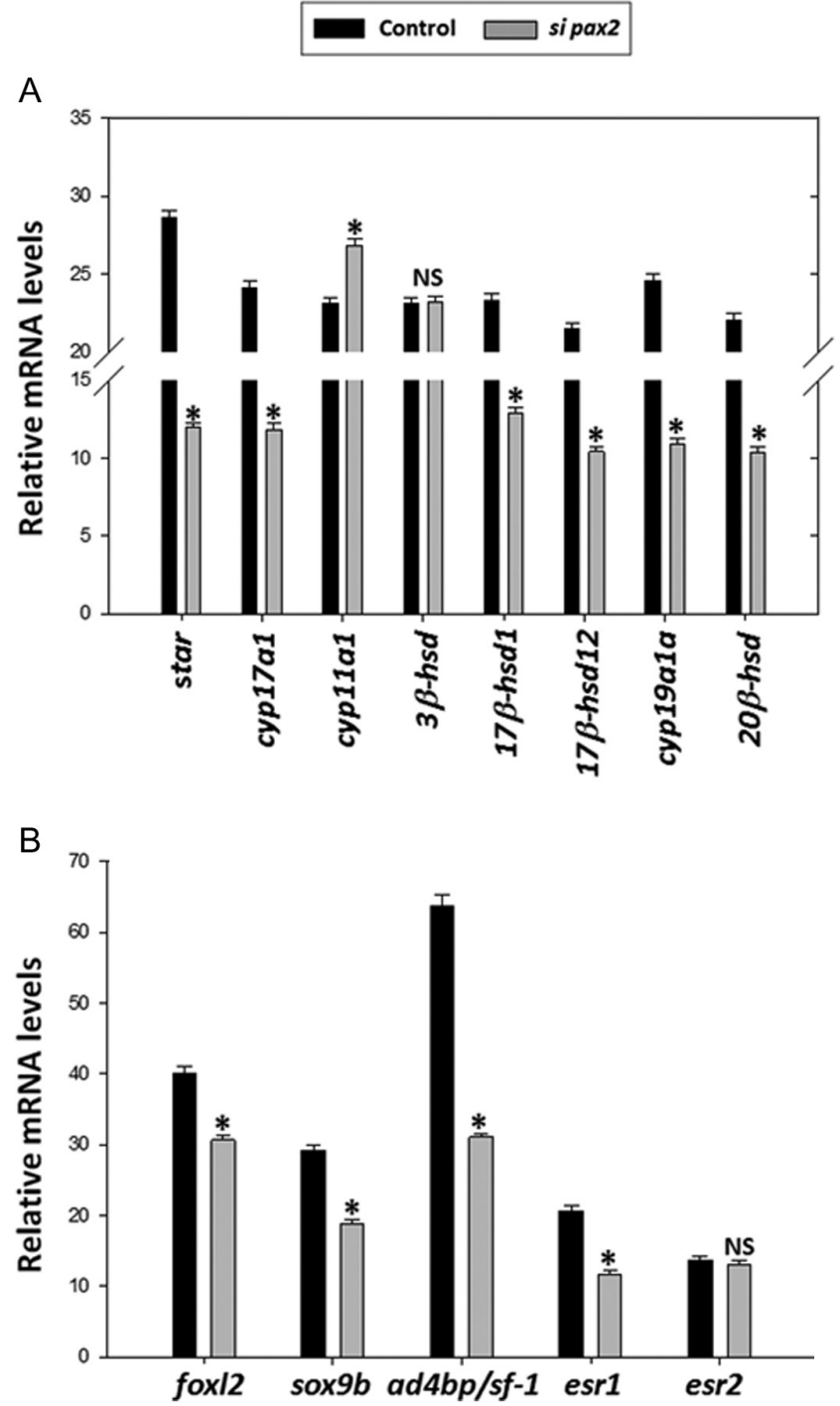

Figure 8

Relative mRNA levels of (A) star and steroidogenic enzymes such as cyp17a1,

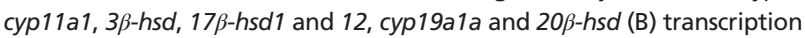
factors, fox/2, sox 9 and ad4bp/sf-1 and estrogen receptors, esr 1 and esr2 in the control and after silencing of pax 2 in catfish. The relative expression was normalized with 185 rRNA expression, and the values were calculated using comparative ct method. All data were expressed as mean \pm S.E.M. (* $P<0.05$; ANOVA followed by SNK test). NS, not significant. 
Silencing of pax2 in catfish ovarian follicles, in vivo at mRNA and protein levels

The expression levels of pax2 reduced significantly $(P<0.005)$ by $80 \%$ at $1 \mu \mathrm{g}$ concentration after $72 \mathrm{~h}$ compared with control (Fig. 7A). The expression levels of pax2, wnt4 and wnt5 did not show any significant change after transfecting with control siRNA (Fig. 7B) compared with those of the respective control sample. The protein levels of Pax 2 and Wnt 4 also reduced at the same time, whereas there was no change observed for the protein levels of control antibody, $\beta$-tubulin (Fig. 7C). Considering this, catfish ovary silenced with (Si)pax2 at $1 \mu \mathrm{g}$ concentration for $72 \mathrm{~h}$ was taken for further analysis of transcript levels of several genes chosen for this study. To substantiate our in vitro results, we had tested a few other steroidogenic enzyme genes after the silencing of Pax2, in vivo.

\section{Change in the expression of various transcripts involved in the ovarian development after silencing pax 2 in catfish, in vivo}

The expression of wnt4 and wnt5 reduced significantly $(P<0.001)$ by $50 \%$ and $65 \%$, respectively (Fig. $7 \mathrm{~A})$ on silencing pax 2 , compared with the control. The expression of star reduced significantly $(P<0.001)$ by $60 \%$ compared with that of the control. The expression of cyp17a1 reduced significantly $(P<0.001)$ by $50 \%$, whereas that of cyp11a1 increased significantly $(P<0.001)$ to 0.8 fold compared with control (Fig. 8A). 3 $\beta$-hsd did not show any change, whereas $50 \%$ significant $(P<0.05)$ reduction was observed in 17ß-hsd 1 and 12 (Fig. 8A). The expression of cyp19a1a reduced significantly $(P<0.05)$ by $50 \%$, whereas that of $20 \beta$-hsd reduced significantly $(P<0.001)$ by $45 \%$ compared with control (Fig. $8 \mathrm{~A}$ ). The expression of foxl2 reduced significantly $(P<0.05)$ by $10 \%$ (Fig. $8 \mathrm{~B}$ ). The expression of sox $9 b$ reduced significantly $(P<0.05)$ by $20 \%$ (Fig. $8 \mathrm{~B}$ ) and that of $a d 4 b p / s f-1$ reduced by $65 \%$, significantly $(P<0.001)$, whereas the expression of esr1 reduced significantly $(P<0.05)$ by $30 \%$, and there was no change in esr2 compared with that in controls (Fig. 8B).

\section{Change in the levels of steroid hormones, $E_{2}$ and $17 \alpha, 20 \beta$-DP after silencing pax2 in catfish, in vivo}

The levels of serum $E_{2}$ (Fig. 9A) significantly decreased to $28 \%(P<0.05)$ after silencing pax2, whereas the levels of $17 \alpha, 20 \beta$-DP (Fig. 9B) did not show any significant change compared with those of control.
A
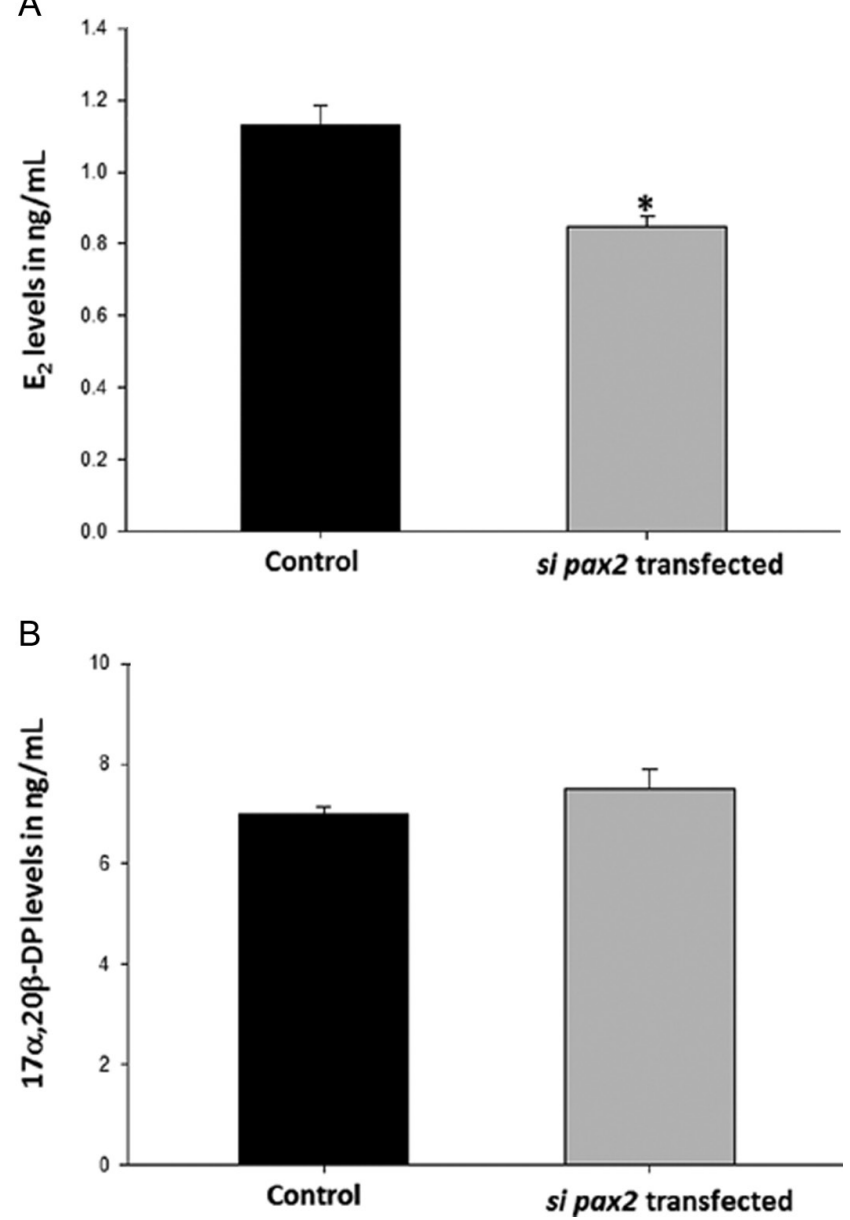

Figure 9

Relative serum levels of $(A)$ estradiol-17 $\beta\left(E_{2}\right)$ and (B) 17 $\alpha, 20 \beta$-dihydroxy-4pregnen-3-one (17 $\alpha, 20 \beta-D P)$ in the control and after silencing of pax2 in catfish. The relative expression was normalized with 185 rRNA expression, and the values were calculated using comparative ct method. All data were expressed as mean \pm S.E.M. $\left({ }^{*} P<0.05 ;\right.$ ANOVA followed by SNK test $)$.

\section{Discussion}

In this study, the full-length cDNAs of the members of Pax family of transcription factors, pax 1 and pax 2 , and a partial cDNA fragment of pax 9 were obtained from catfish. Considering the predominant expression of pax 2 in ovary in comparison with pax 1 and pax9, a detailed study was conducted on the former to analyze its role during ovarian development and recrudescence in catfish. The deduced aa sequence of catfish Pax 2 showed its characteristic features of the Pax family with conserved DNA-binding helix-turnhelix motif, Pax and a C-terminal Pax2 domain. Although there are two transcript variants in other teleostean member, D. rerio, it is not evident in this species even after repeated RACE analysis and genomic PCR with the primers designed onto two neighboring highly conserved

Published by Bioscientifica Ltd 
exons flanking a variable intron. ClustalW alignments showed its homology with the conserved Pax domain of other vertebrates including teleosts.

Expression levels of pax2 in ovary indicate its plausible role in ovarian development as it plays an important role in thyroid follicle development (Wendl et al. 2002), which might have other effects in consequence, as impaired thyroidal status affects gonadal development and recrudescence (Swapna et al. 2006, Swapna \& Senthilkumaran 2007). In fact, thyroidstimulating hormone receptor appears to play critical roles in gametogenesis rather than embryogenesis (GotoKazeto et al. 2009). Higher expression of pax2 in other tissues like brain and kidney indicates its role as in that of zebrafish, where it has a prominent role for mid-hind brain boundary development (Lun \& Brand 1998), and it is required in multiple aspects of pronephros development including tubule and duct epithelial differentiation and cloaca morphogenesis (Majumdar et al. 2000). The expression of this transcript in other tissues also supports its role in organ development as being an early expressed embryonic gene. Considering these findings, it is plausible to presume a role for Pax2 in gonadal development. Furthermore, ontogeny analysis indicates its role from the early stage of development of the animals and that it is sex dependent from the critical stage of sexual differentiation and is in favor of females indicating its importance in gonadal differentiation as that of other transcription factors like foxl2, ad $4 b p / s f-1$ and sox $9 b$ analyzed in catfish (Sudhakumari \& Senthilkumaran 2013). The relatively high expression of pax 2 in preparatory and pre-spawning phases of ovarian reproductive cycle of catfish indicates its prominent role in recrudescence. Although the relative levels of pax 2 in testis are low compared with those in ovary during reproductive cycle, its presence may contribute to testicular development. However, its putative role is not yet known. Induction of pax2 levels using hCG indicates its role in pre-spawning/spawning and its regulation by gonadotropins. Localization of mRNA through ISH in ovary showed its expression in peri-nucleolar, pre-vitellogenic and vitellogenic oocytes, and follicular layer of vitellogenic and postvitellogenic oocytes. Similar pattern was evident during immunoreactivity with heterologous antibody in oocytes, and also a clear protein band from ovarian protein lysate could be observed. Expression levels in different stages of follicles seem to be of high quantities earlier in developmental stages. By and large, these results creditably support the prime significance of Pax2 in ovarian development and recrudescence.
To analyze its function in ovarian development, pax2 transient silencing experiments were performed in catfish primary culture of ovarian follicles, in vitro, and also through ovary-targeted injection of siRNA into the catfish, in vivo. Although different cell types from follicular primary culture were not characterized, steady expression of pax 2 and measurement of different ovaryrelated transcripts confirm the stability. To alleviate the off-target effects, we used custom-synthesized catfish-specific esiRNA, which is an endoribonucleaseprepared heterogeneous mixture of siRNA pools with multiple triggers that target the same mRNA sequence. In addition, control esiRNA was used to validate our findings. After silencing of pax 2 mRNA and protein levels, the expression patterns of Wnt signaling molecules, various transcripts encoding steroidogenic enzymes and transcription factors, which are known to be essential for ovarian development in catfish were analyzed. There is a 50\% reduction in the expression pattern of most of the transcripts analyzed both in vitro and in vivo indicating that pax 2 affects their expression through direct or indirect action. Upon silencing Pax2, down regulation of the expression of signaling molecules, wnt 4 and wnt5, indicates a direct interaction of Pax 2 in catfish as proved in the kidney of mammals (Torban et al. 2006, Tamimi et al. 2008). There is a reduction in the gene encoding Star, a transport protein for cholesterol within the mitochondria, which is a rate-limiting step in steroidogenesis (Sreenivasulu et al. 2009). This change might have been due to Ad4bp/ sf-1, which plays an important role in the regulation of many steroidogenic enzymes, especially cytochrome P450 steroid hydroxylases/aromatase (Yoshiura et al. 2003, Senthilkumaran et al. 2004) and steroidogenic acute regulatory protein, which might have reduced the transcript levels of cyp17a1 and star (Raghuveer et al. 2011). The decreased expression of transcription factor, Foxl2, a member of the forkhead/HNF-3-related family, which is involved in ovarian differentiation and many other developmental processes (Sridevi \& Senthilkumaran 2011) might have reduced the expression of $a d 4 b p / s f-1$, which eventually downregulated cyp19a1a transcription as they transcriptionally interact together during ovarian recrudescence of teleosts (Yoshiura et al. 2003, Yamaguchi et al. 2007, Wang et al. 2007, Rasheeda et al. 2010). Decreased expression of another transcription factor, Sox9b that is critical for ovarian differentiation in catfish (Raghuveer \& Senthilkumaran 2010) might also be attributed to the low expression of ad $4 \mathrm{bp} / \mathrm{sf}-1$. Interestingly, there is no change in the

Published by Bioscientifica Ltd. 
expression of $3 \beta$-hsd, whereas cyp11a1 was upregulated after Pax2 silencing in catfish, in vivo. Although the reason for such differential response is not clear, it reiterates that the siRNA of pax 2 treatment resulted in a varied response. Interestingly, both the steroidogenic enzyme genes play an essential role in the gonadal development and recrudescence in catfish (Raghuveer \& Senthilkumaran 2012, Rajakumar \& Senthilkumaran $2014 b$ ). There is a decrease in transcript levels of steroidogenic enzymes, $17 \beta$-hsd 1 and 12 , which may perhaps modulate gametogenesis and gamete maturation in catfish (Rajakumar \& Senthilkumaran 2014c). There is a reduction in the expression pattern of $20 \beta$-hsd, the enzyme responsible for oocyte maturation in teleosts, along with cyp19a1a and cyp17a1 (Senthilkumaran et al. 2004, Sreenivasulu \& Senthilkumaran 2009a,b), which were effected through $a d 4 b p / s f-1$, indicating the role of pax 2 in oocyte growth and maturation as a consequence of events. Nevertheless, it remains to be seen whether pax2 also regulates CREB, which controls the oocyte growth and maturation in teleosts (Senthilkumaran et al. 2015). There is a reduction in the expression of esr 1 , in accordance with the steroidogenic enzyme genes, which might indicate probable intermediate actions in imparting its effects on ovarian development, where esrs serve as ligand-dependent transcription factors for estrogen secretion (Parker et al. 1991, Filby \& Tyler 2005). There is no change in esr 2 that might have compensating action for esr 1 changes. Marginally significant reduction in the levels of $\mathrm{E}_{2}$ after silencing pax 2 might validate altered transcript levels of steroidogenic enzymes responsible for $\mathrm{E}_{2}$ production. Reduction in the transcript levels of $20 \beta$-hsd, the enzyme responsible for oocyte maturation did not alter $17 \alpha, 20 \beta$-DP levels indicating that the transient silencing at the recrudescent stage (mid-preparatory phase) of fish might have less immediate effects at functional level.

Taken together, it is possible to suggest that the modulation of transcripts involved in ovarian steroidogenesis might have been due to Pax2 regulation either on direct binding with proximal promoters of steroidogenic enzyme genes, as there is the presence of Pax2-binding motifin steroidogenic enzyme genes and also indirectly through Pax2-mediated wnt4 downregulation as that of zebrafish and mammals in which wnt4 is known as a probable regulator of steroidogenesis (Kocer et al. 2009, Sreenivasan et al. 2014). It is possible that in teleosts too, Pax2 might operate its signaling through wnt $4 / 5$ as reported in mammals (Zhou 2012). In fact, our extended work on this line identified functional
Pax2-binding site in $w n t 5$ promoter motif with a synergistic expression pattern (Prathibha Y \& Senthilkumaran B, unpublished observations). The effects on steroidogenesis are perhaps partly mediated through Wnt signaling in a Pax2-dependent manner accrediting the importance of pax 2 in ovarian development and recrudescence of catfish. Although these findings provide introductory evidence on the interaction of Pax2-wnt4/5 in terms of ovarian steroidogenesis and development, this study for the first time provides a basis for such interaction in a lower vertebrate using transcript level analysis. These results may not implicate the absence of regulation of steroidogenesis by Pax 2 in testis as there is a commonality of the endocrine processes in both sexes, which needs to be explored in detail.

\section{Conclusion}

This study demonstrates that pax 2 plays an important role in ovarian development and recrudescence of catfish by regulating steroidogenesis either directly or indirectly through Wnt signaling pathway as evident from transient gene-silencing experiments in catfish, in vivo and ovarian follicle primary culture, in vitro.

\section{Declaration of interest}

The authors declare that there is no conflict of interest that could be perceived as prejudicing the impartiality of the research reported.

\section{Funding}

A grant-in-aid (SR/SO/AS-06/2012) from the Department of Science and Technology, India to B S supported this work mostly. Y P is thankful to the Council of Scientific and Industrial Research, India, for junior and senior research fellowships. B $S$ is a recipient of the Department of Biotechnology-TATA innovation fellowship (BT/HRD/35/01/02/2013), which is acknowledged. Grant support by the University Grants Commission, India through University for Potential Excellence program (UPE-II) to the Department of Animal Biology is also acknowledged.

\section{References}

Akhtar S \& Benter IF 2007 Nonviral delivery of synthetic siRNAs in vivo. Journal of Clinical Investigation 117 3623-3632. (doi:10.1172/ JCI33494)

Blake JA \& Ziman MR 2014 Pax genes: regulators of lineage specification and progenitor cell maintenance. Development 141 737-751. (doi:10.1242/dev.091785)

Chapalamadugu KC, Murdoch BM, Robison BD, Hill RA \& Murdoch GK 2015 Oncorhynchus mykiss pax7 sequence variations with comparative analyses against other teleost species. Springer Plus 4263. (doi:10.1186/s40064-015-1030-7)

Drummond AE 2006 The role of steroids in follicular growth. Reproductive Biology and Endocrinology 4 16. (doi:10.1186/1477-7827-4-16)

Published by Bioscientifica Ltd. 
Filby AL \& Tyler CR 2005 Molecular characterization of estrogen receptors $1,2 \mathrm{a}$, and $2 \mathrm{~b}$ and their tissue and ontogenic expression profiles in fat head minnow (Pimephales promelas). Biology of Reproduction 73 648-662. (doi:10.1095/biolreprod.105.039701)

Froehlich JM, Galt NJ, Charging MJ, Meyer BM \& Biga PR 2013 In vitro indeterminate teleost myogenesis appears to be dependent on Pax3. In Vitro Cellular and Developmental Biology Animal 4 371-385. (doi:10.1007/s11626-013-9616-2)

Goto-Kazeto R, Kazeto Y \& Trant JM 2009 Molecular cloning, characterization and expression of thyroid-stimulating hormone receptor in channel catfish. General and Comparative Endocrinology 161 313-319. (doi:10.1016/j.ygcen.2009.01.009)

Jamnongjit M \& Hammes SR 2006 Ovarian steroids: the good, the bad, and the signals that raise them. Cell Cycle 5 1178-1183. (doi:10.4161/ cc.5.11.2803)

Kacperczyk A, Jagla T \& Daczewska M 2009 Pax-3 and Pax-7 label muscle progenitor cells during myotomal myogenesis in Coregonus lavaretus (Teleostei: Coregonidae). Anatomia Histologia Embryologia 38 411-418. (doi:10.1111/j.1439-0264.2009.00961.x)

Kocer A, Reichmann J, Best D \& Adams IR 2009 Germ cell sex determination in mammals. Molecular Human Reproduction $\mathbf{1 5}$ 205-213. (doi:10.1093/molehr/gap008)

Lakowski J, Majumder A \& Lauderdale JD 2007 Mechanisms controlling Pax6 isoform expression in the retina have been conserved between teleosts and mammals. Developmental Biology 307 498-520. (doi:10.1016/j.ydbio.2007.04.015)

Lehri GK 1968 Cyclical changes in the ovary of the catfish Clarias batrachus (Linn.). Acta Anatomica 69 105-124. (doi:10.1159/000143067)

Li CW, Zhou R \& Ge W 2012 Differential regulation of gonadotropin receptors by bone morphogenetic proteins in the zebrafish ovary. General and Comparative Endocrinology 176 420-425. (doi:10.1016/j. ygcen.2011.12.032)

Lun K \& Brand M 1998 A series of no isthmus (noi) alleles of the zebrafish pax2.1 gene reveals multiple signaling events in development of the midbrain-hindbrain boundary. Development 125 3049-3062.

Mackereth MD, Kwak SJ, Fritz A \& Riley BB 2005 Zebrafish pax8 is required for otic placode induction and plays a redundant role with Pax2 genes in the maintenance of the otic placode. Development 132 371-382. (doi:10.1242/dev.01587)

Majumdar A, Lun K, Brand M \& Drummond IA 2000 Zebrafish no isthmus reveals a role for pax2.1 in tubule differentiation and patterning events in the pronephric primordia. Development 127 2089-2098.

Parker MG, Fawell SE, Danielian P \& Arbuckle N 1991 Role of ligand in oestrogen receptor function. Biochemical Society Transactions 19 897-899. (doi:10.1042/bst0190897)

Parrilla M, Lillo C, Herrero-Turrión MJ, Arévalo R, Aijón J, Lara JM \& Velasco A 2012 Characterization of Pax2 expression in the goldfish optic nerve head during retina regeneration. PLOS ONE 7 e32348. (doi:10.1371/journal.pone.0032348)

Radonić A, Thulke S, Mackay IM, Landt O, Siegert W \& Nitsche A 2004 Guideline to reference gene selection for quantitative real-time PCR. Biochemical and Biophysical Research Communications 313 856-862. (doi:10.1016/j.bbrc.2003.11.177)

Raghuveer K \& Senthilkumaran B 2010 Isolation of sox9 duplicates in catfish: localization, differential expression pattern during gonadal development and recrudescence, and hCG-induced up-regulation of sox9 in testicular slices. Reproduction 140 477-487. (doi:10.1530/REP10-0200)

Raghuveer K \& Senthilkumaran B 2012 Cloning and expression of $3 \beta$-hydroxysteroid dehydrogenase during gonadal recrudescence and after hCG induction in the air-breathing catfish, Clarias gariepinus. Steroids 77 1133-1140. (doi:10.1016/j.steroids.2012.06.002)
Raghuveer K, Senthilkumaran B, Sudhakumari CC, Sridevi P, Rajakumar A, Singh R, Murugananthkumar R \& Majumdar KC 2011 Dimorphic expression of various transcription factor and steroidogenic enzyme genes during gonadal ontogeny in the airbreathing catfish, Clarias gariepinus. Sexual Development 5 213-223. (doi:10.1159/000328823)

Rajakumar A \& Senthilkumaran B 2014a Expression analysis of sox3 during testicular development, recrudescence, and after hCG induction in catfish, Clarias batrachus. Sexual Development 8 376-386. (doi:10.1159/000368864)

Rajakumar A \& Senthilkumaran B 2014b Expression analysis of cyp11a1 during gonadal development, recrudescence and after hCG induction and sex steroid analog treatment in the catfish, Clarias batrachus. Comparative Biochemistry and Physiology B 176 42-47. (doi:10.1016/j. cbpb.2014.07.007)

Rajakumar A \& Senthilkumaran B 2014c Molecular cloning and expression analysis of $17 \beta$-hydroxysteroid dehydrogenase 1 and 12 during gonadal development, recrudescence and after in vivo hCG induction in catfish, Clarias batrachus. Steroids 92 81-89. (doi:10.1016/j.steroids.2014.09.009)

Rajakumar A, Singh R, Chakrabarty S, Murugananthkumar R, Laldinsangi C, Prathibha Y, Sudhakumari CC, Dutta-Gupta A \& Senthilkumaran B 2012 Endosulfan and flutamide impair testicular development in the juvenile Asian catfish, Clarias batrachus. Aquatic Toxicology 110-111 123-132. (doi:10.1016/ j.aquatox.2011.12.018)

Rasheeda MK, Sridevi P \& Senthilkumaran B 2010 Cytochrome P450 aromatases: impact on gonadal development, recrudescence and effect of hCG in the catfish, Clarias gariepinus. General and Comparative Endocrinology 167 234-245. (doi:10.1016/j. ygcen.2010.03.009)

Senthilkumaran B, Yoshikuni M \& Nagahama YA 2004 A shift in steroidogenesis occurring in ovarian follicles prior to oocyte maturation. Molecular and Cellular Endocrinology 215 11-18. (doi:10.1016/j.mce.2003.11.012)

Senthilkumaran B, Sreenivasulu G, Wang DS, Sudhakumari CC, Kobayashi T \& Nagahama Y 2015 Expression patterns of CREBs in oocyte growth and maturation of fish. PLOS ONE 10 e0145182. (doi:10.1371/journal.pone.0145182)

Sirotkin AV 2010 Transcription factors and ovarian functions. Journal of Cellular Physiology 225 20-26. (doi:10.1002/jcp.22248)

Sreenivasan R, Jiang J, Wang X, Bártfai R, Kwan HY, Christoffels A \& Orbán L 2014 Gonad differentiation in zebrafish is regulated by the canonical Wnt signaling pathway. Biology of Reproduction 9045. (doi:10.1095/biolreprod.113.110874)

Sreenivasulu G \& Senthilkumaran B 2009a New evidences for the involvement of 20ß-hydroxysteroid dehydrogenase in final oocyte maturation of air-breathing catfish. General and Comparative Endocrinology 163 259-269. (doi:10.1016/j.ygcen.2009.04.022)

Sreenivasulu G \& Senthilkumaran B 2009b A role for cytochrome P450 $17 \alpha$-hydroxylase and c17-20 lyase during shift in steroidogenesis occurring in ovarian follicles prior to oocyte maturation. Journal of Steroid Biochemistry and Molecular Biology 115 77-85. (doi:10.1016/j. jsbmb.2009.03.004)

Sreenivasulu G, Sridevi P, Sahoo PK, Swapna I, Ge W, Kirubagaran R, Dutta-Gupta A \& Senthilkumaran B 2009 Cloning and expression of StAR during gonadal cycle and hCG-induced oocyte maturation of air-breathing catfish, Clarias gariepinus. Comparative Biochemistry and Physiology B 154 6-11. (doi:10.1016/j.cbpb.2009.04.010)

Sridevi P \& Senthilkumaran B 2011 Cloning and differential expression of FOXL2 during ovarian development and recrudescence of the catfish, Clarias gariepinus. General and Comparative Endocrinology 174 259-268. (doi:10.1016/j.ygcen.2011.08.015)

Sudhakumari CC \& Senthilkumaran B 2013 Expression profiling of various marker genes involved in gonadal differentiation of teleosts: http://joe.endocrinology-journals.org

DOI: 10.1530/JOE-16-0103
(C) 2016 Society for Endocrinology Printed in Great Britain
Published by Bioscientifica Ltd. 
molecular understanding of sexual plasticity. In Sexual Plasticity and Gametogenesis in Fishes, Ch XXIV, pp. 401-422. Ed B Senthilkumaran. Long Island, NY, USA: Nova Science.

Swapna I \& Senthilkumaran B 2007 Thyroid hormones modulate the hypothalamo-hypophyseal-gonadal axis in teleosts: molecular insights. Fish Physiology and Biochemistry 33 335-345. (doi:10.1007/ s10695-007-9165-2)

Swapna I, Rajasekhar M, Supriya A, Raghuveer K, Sreenivasulu G, Rasheeda MK, Majumdar KC, Kagawa H, Tanaka H, Dutta-Gupta A, et al. 2006 Thiourea-induced thyroid hormone depletion impairs testicular recrudescence in the air-breathing catfish, Clarias gariepinus. Comparative Biochemistry and Physiology A 144 1-10. (doi:10.1016/j.cbpa.2006.01.017)

Tamimi Y, Ekuere U, Laughton N \& Grundy P 2008 WNT5A is regulated by PAX2 and may be involved in blastemal predominant Wilms tumorigenesis. Neoplasia 10 1470-1480. (doi:10.1593/neo.08442)

Teves ACC, Granneman JCM, van Dijk W \& Bogerd J 2003 Cloning and expression of a functional estrogen receptor- $\alpha$ from African catfish (Clarias gariepinus) pituitary. Journal of Molecular Endocrinology $\mathbf{3 0}$ 173-185. (doi:10.1677/jme.0.0300173)

Torban E, Dziarmaga A, Iglesias D, Chu LL, Vassilieva T, Little M, Eccles M, Discenza M, Pelletier J \& Goodyer P 2006 PAX2 activates WNT4 expression during mammalian kidney development. Journal of Biological Chemistry 281 12705-12712. (doi:10.1074/jbc.M513181200)

Torres M, Gómez-Pardo E \& Gruss P 1996 Pax2 contributes to inner ear patterning and optic nerve trajectory. Development 122 3381-3391.

Torres M, Gómez-Pardo E, Dressler GR \& Gruss P 1995 Pax-2 controls multiple steps of urogenital development. Development 121 4057-4065.
Treisman J, Harris E \& Desplan C 1991 The paired box encodes a second DNA-binding domain in the paired homeo domain protein. Genes and Development 5 594-604. (doi:10.1101/gad.5.4.594)

Wang DS, Kobayashi T, Zhou LY, Paul-Prasanth B, Ijiri S, Sakai F, Okubo K, Morohashi K \& Nagahama Y 2007 Foxl2 up-regulates aromatase gene transcription in a female-specific manner by binding to the promoter as well as interacting with ad4 binding protein/steroidogenic factor 1. Molecular Endocrinology 21 712-725. (doi:10.1210/me.2006-0248)

Wendl T, Lun K, Mione M, Favor J, Brand M, Wilson SW \& Rohr KB 2002 Pax2.1 is required for the development of thyroid follicles in zebrafish. Development 129 3751-3760.

Yamaguchi T, Yamaguchi S, Hirai T \& Kitano T 2007 Follicle-stimulating hormone signaling and Foxl 2 are involved in transcriptional regulation of aromatase gene during gonadal sex differentiation in Japanese flounder, Paralichthys olivaceus. Biochemical and Biophysical Research Communications 359 935-940. (doi:10.1016/j. bbrc.2007.05.208)

Yoshiura Y, Senthilkumaran B, Watanabe H, Oba Y, Kobayashi T \& Nagahama Y 2003 Synergistic expression of Ad4BP/SF-1 and cytochrome P-450 aromatase (ovarian type) in the ovary of Nile tilapia, Oreochromis niloticus, during vitellogenesis suggests transcriptional interaction. Biology of Reproduction 68 1545-1553. (doi:10.1095/biolreprod.102.010843)

Zhou TB 2012 Signaling pathways of PAX2 and its role in renal interstitial fibrosis and glomerulosclerosis. Journal of Receptors and Signal Transduction Research 32 298-303. (doi:10.3109/10799893.2012. 738231)

Received in final form 7 September 2016

Accepted 9 September 2016
๑) 2016 Society for Endocrinology Printed in Great Britain 